\title{
Complete Double Epoxidation of Divinylbenzene Using Mn(porphyrin)-Based Porous Organic Polymers
}

\author{
Kainan Zhang, Omar K. Farha,* Joseph T. Hupp,* and SonBinh T. Nguyen*
}

Department of Chemistry and International Institute for Nanotechnology, Northwestern University, 2145 Sheridan Road, Evanston, Illinois 60208-3113, United States

\section{Supporting Information}

ABSTRACT: A series of porphyrin-based porous organic polymers (PPOPs) were synthesized in excellent yields via the Yamamoto-Ullmann couplings of tetrabromo spirobifluorene with several brominated porphyrin monomers. After isolation and demetalation, the metal-free PPOP can be postsynthetically metalated to form a $\mathrm{Mn}^{\mathrm{III}}-\mathrm{PPOP}$ that is catalytically active toward the selective double-epoxidation of divinylbenzene to divinylbenzene dioxide.

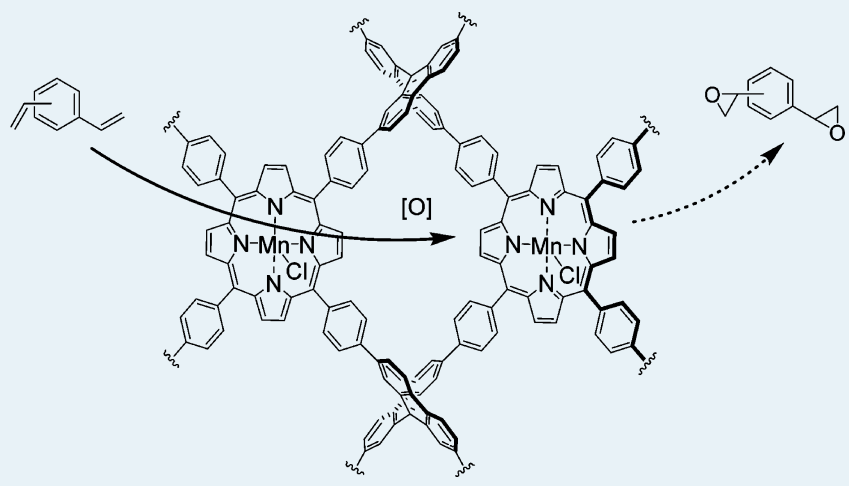

KEYWORDS: Mn(porphyrin), porous organic polymer, epoxidation, divinylbenzene, divinylbenzene dioxide

$\mathrm{T}$ he synthesis of multiepoxides from available multiolefin precursors is a key process in the preparation of epoxy resins, a class of technologically important materials with excellent mechanical and electrical insulating properties as well as good resistances to chemicals and temperature. ${ }^{1}$ Among the multiepoxides that are currently in use, divinylbenzene dioxide (DVBDO) is an important popular and high-tech component in epoxy thermoset formulations for use as coatings, structural components, and modeling composites. ${ }^{2}$ Yet to date, there are only a handful of catalytic processes reported for the preparation of DVBDO, ${ }^{3-5}$ often with low conversion and broad product mixtures. ${ }^{2,4-6}$ Thus, a catalyst that can epoxidize divinylbenzene (DVB) to DVBDO with good conversion and selectivity is highly desirable. Herein, we report a porous organic polymer (POP) catalyst that can successfully accomplish this goal through a microporous environment with multiple catalyst entities that can encapsulate DVB and oxidize both of its olefin groups.

Although metalloporphyrins have been intensively studied as epoxidation catalysts, given their high activities and close biological relevance to natural enzymes, ${ }^{7-13}$ their utilities in homogeneous epoxidation have been rather limited because of several deactivation pathways, such as dimerization ${ }^{13}$ and selfoxidation. ${ }^{14}$ To achieve more stabilized and active catalytic systems, metalloporphyrins have been anchored to solid supports ${ }^{15}$ as well as integrated into porous materials, such as metal organic framworks ${ }^{16-20}$ and porous organic polymers (POPs). ${ }^{2-31}$ In particular, the integration of metalloporphyrins into porous frameworks has been found to lead to unexpected benefits, such as shape and size selectivity ${ }^{26,32}$ and increases in reaction rate as a result of preconcentration effects. ${ }^{29}$ It is this latter effect that prompted us to examine the double epoxidation of DVB inside a microporous metalloporphyrinbased POP. We hypothesize that a preconcentration of DVB inside the pores of an appropriately designed metalloporphyrinbased POP would lead to its complete double epoxidation because of the ability of adjacent catalyst moieties to interact with both vinyl functionalities. As shown below, this is, indeed, the case: excellent catalytic reactivity and high selectivity can be achieved for the double epoxidation of DVB to DVBDO using a microporous POP derived from spirobifluorene and porphyrin-based building blocks.

Although metalloporphyrins have previously been incorporated into POPs ${ }^{22,31}$ and used for sulfide oxidation, alkene expoxidation, ${ }^{31}$ and hydrogen peroxide decomposition, ${ }^{33}$ these early materials have relatively moderate surface areas, which limit the range of substrates and oxidants that can be used. To overcome these limitations, we selected the spirobifluorene monomer $\mathbf{A}$ as the structure-directing comonomer in our synthesis of porphyrin-based POPs (PPOPs) using Yamamoto-Ullmann couplings, ${ }^{34-38}$ given its tendency to afford POP materials with excellent thermostability, high microporosity, and moderate mesoporosity (based on the pore size distribution data, there are micropores at about 7 and $12 \AA$ and a broad hump in the mesoporous region ranging from 20 to $40 \AA) .{ }^{34-37}$ For the porphyrin components, we examined both the dibromide derivatives $\mathbf{1}$ and the tetrabromide

Received: July 3, 2015

Revised: July 9, 2015

Published: July 10, 2015 


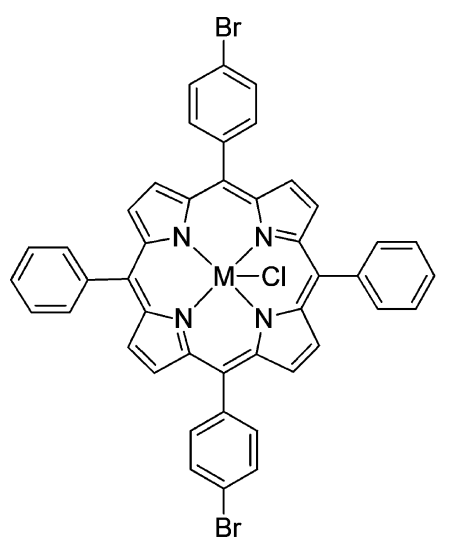

$\mathrm{Fe1}, \mathrm{M}=\mathrm{Fe}$ Mn1, M = Mn

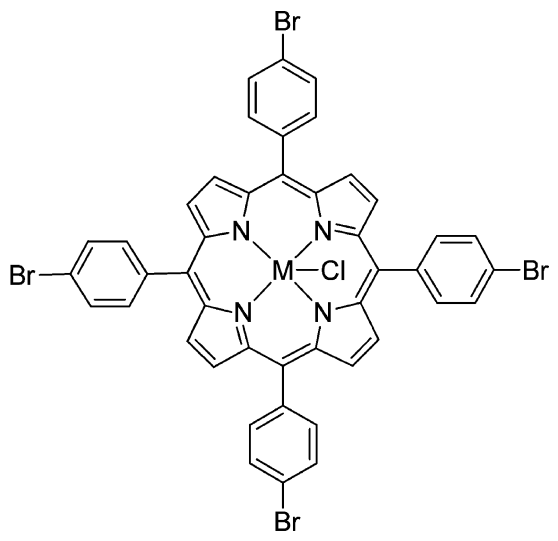

2, $\mathrm{M}=(\mathrm{H})_{2}$ $\mathrm{Fe2}, \mathrm{M}=\mathrm{Fe}$ Mn2, $M=M n$

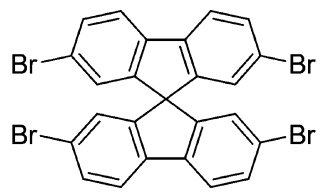

A

Figure 1. Monomers for Yamamoto-Ullmann coupling.

derivatives 2 (Figure 1). Curiously, although the couplings between $\mathbf{A}$ and either the free-base porphyrins (1 and 2) or the $\mathrm{Fe}$ (porphyrin) monomers (Fe1 and Fe2) under various stoichiometric ratios proceed in good yields (see Supporting Information (SI)), the analogous couplings with the $\mathrm{Mn}$ (porphyrin) monomers failed. Presumably, the $\mathrm{Ni}(\mathrm{COD})_{2}$ reagent may have been oxidized by the $\mathrm{Mn}^{\mathrm{III}}$ center, leading to deactivation.

As is common in Yamamoto-Ullmann couplings, a strong acidic workup is required to remove all the $\mathrm{Ni}$ side products. Upon this acidic workup, the Fe-containing PPOPs $\mathbf{A}_{n} \mathbf{F e} \mathbf{l}$ and $\mathrm{A}_{n} \mathrm{Fe} 2$ (subscript $n=1-3$, indicating the relative stoichiometry of A vs those for Fe1 and Fe2), readily demetallate to form partially metalated or fully demetalated PPOPs (Scheme 1, Table 1). Complete demetalation can be achieved by a second acid treatment at $85{ }^{\circ} \mathrm{C}$, giving rise to the corresponding freebase PPOPs ${ }^{\mathrm{fb}} \mathrm{A}_{n} \mathrm{Fe} \mathbf{1}$ and ${ }^{\mathrm{fb}} \mathrm{A}_{n} \mathrm{Fe}$. In general, increasing the ratio of spirobifluorene $\mathbf{A}$ to the porphyrin monomers led to increases in the specific surface areas (ssa's) (Table 1, cf. entries 1-3 and entries 4-6) of the resulting free-base PPOPs. Presumably, this can be attributed to a higher degree of crosslinking possible in A-rich formulations.

Interestingly, $\mathbf{A}_{2} 2$, the PPOP derived from the free-base porphyrin monomer 2 still retains a significant amount of $\mathrm{Ni}$ after workup (see Table S1, entry 6 in the SI), presumably as a result of in situ metalation by the $\mathrm{NiBr}_{2}$ side products. Nevertheless, most of the $\mathrm{Ni}$ contaminants can be removed upon a second, more rigorous acid treatment at higher temperatures $\left(85{ }^{\circ} \mathrm{C}\right.$ and $\left.10 \mathrm{~h}\right)$ yielding a free-base PPOP $\left({ }^{\mathrm{fb}} \mathrm{A}_{2} 2\right)$ with BET surface area (Table 1, entry 7 ) and total pore volume that are almost twice those of ${ }^{\mathrm{fb}} \mathrm{A}_{2} \mathbf{F e} 2$, the demetalated free-base PPOP derived from $\mathbf{A}_{\mathbf{2}} \mathbf{F e} 2$, which has the same spirobifluorene/porphyrin stoichiometry (Table 1 , cf. entries 5 and 7). As expected for a material with aromatic $\mathrm{C}-\mathrm{C}$ connections, PPOP ${ }^{\mathrm{fb}} \mathbf{A}_{\mathbf{2}} \mathbf{2}$ is highly stable: it retains a high surface area $\left(1540 \mathrm{~m}^{2} / \mathrm{g}\right)$ after being exposed to either concentrated hydrochloric acid or $4 \mathrm{M}$ aqueous sodium hydroxide (see Figure S56 in the SI).
Metalation of both ${ }^{\mathrm{fb}} \mathrm{A}_{2} 2$ and ${ }^{\mathrm{fb}} \mathrm{A}_{2} \mathrm{Fe} 2$ with $\mathrm{MnCl}_{2}$. $4 \mathrm{H}_{2} \mathrm{O}^{39-45}$ was carried out under previously established conditions $^{31}$ (Scheme 1). Interestingly, ${ }^{\mathbf{f b}} \mathbf{A}_{\mathbf{2}} \mathbf{F e} \mathbf{2}$ can be metalated near quantitatively, but ${ }^{\mathrm{fb}} \mathbf{A}_{2} 2$ is metalated only to about $67 \%$. Treating this metalated material with additional $\mathrm{MnCl}_{2} \cdot 4 \mathrm{H}_{2} \mathrm{O}$ under the same conditions does not lead to any further increase in metal loadings. Consistent with this observation, the diffuse-reflectance UV-vis spectrum of the $\mathbf{M n}-{ }^{\mathrm{fb}} \mathbf{A}_{2} \mathbf{2}$ material (Figure S61 in the SI) also shows residual bands due to nonmetalated materials.

Metalation only moderately decreases the surface areas for

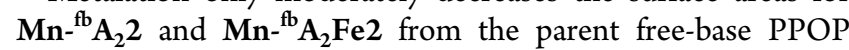
(Figure 2; Table 1, cf. entries 3 vs 8 and 7 vs 9, respectively). Notably, $\mathbf{M n}-{ }^{\mathrm{fb}} \mathbf{A}_{2} \mathbf{2}$ retained most of the mesoporosity of the parent PPOP (Figure 3), which would be beneficial in applications such as catalysis in which mass-transport limitation can be quite important. However, the pore size distribution data for $\mathbf{M n}-{ }^{\mathrm{fb}} \mathbf{A}_{2} \mathbf{F e} 2$ shows almost complete reduction of mesoporosity (Figure 3), a fact that is supported by a reduction of the hysteresis in the $\mathrm{N}_{2}$ isotherms (Figure 2). Nevertheless, the dominant remaining micropore $(\sim 11 \AA)$ for this material is still large enough for DVB $(\sim 7 \AA)$ and DVBDO $(\sim 9 \AA)$ to access.

$\mathbf{M n}-{ }^{\mathrm{fb}} \mathbf{A}_{2} \mathbf{2}$ was then evaluated as a catalyst for the epoxidation reaction of styrene and DVB in the presence of 2-(tertbutylsulfonyl)iodosylbenzene (5) oxidant (Scheme 2). ${ }^{31,46,47}$ As shown in Figure 4, the epoxidation of styrene affords a good yield $(80 \%)$ of styrene oxide with no significant mass loss (see Figure S63 in the SI for the NMR spectra of the reaction mixture). This is in stark contrast to the homogeneous $(\mathrm{TPP}) \mathrm{MnCl}$ analogue $(\mathrm{TTP}=$ meso-tetraphenylporphyrinato dianion), which affords a lower yield of styrene oxide in addition to the overoxidized product benzaldehyde and the isomerization product phenyl acetylaldehyde. This homogeneous catalyst also decomposed much more easily, as shown by the change in the conversion profile after $\sim 15 \mathrm{~h}$ (Figure 4 ).

Consistent with the aforementioned promising styrene oxidation results, both $\mathbf{M n}-{ }^{\mathrm{fb}} \mathbf{A}_{2} \mathbf{2}$ and $\mathbf{M n}-{ }^{\mathrm{fb}} \mathbf{A}_{2} \mathbf{F e} 2$ show comparable good yields and selectivities toward the complete 
Scheme 1. A Schematic Illustration of PPOP Synthesis and Subsequent Demtallation and Metallation

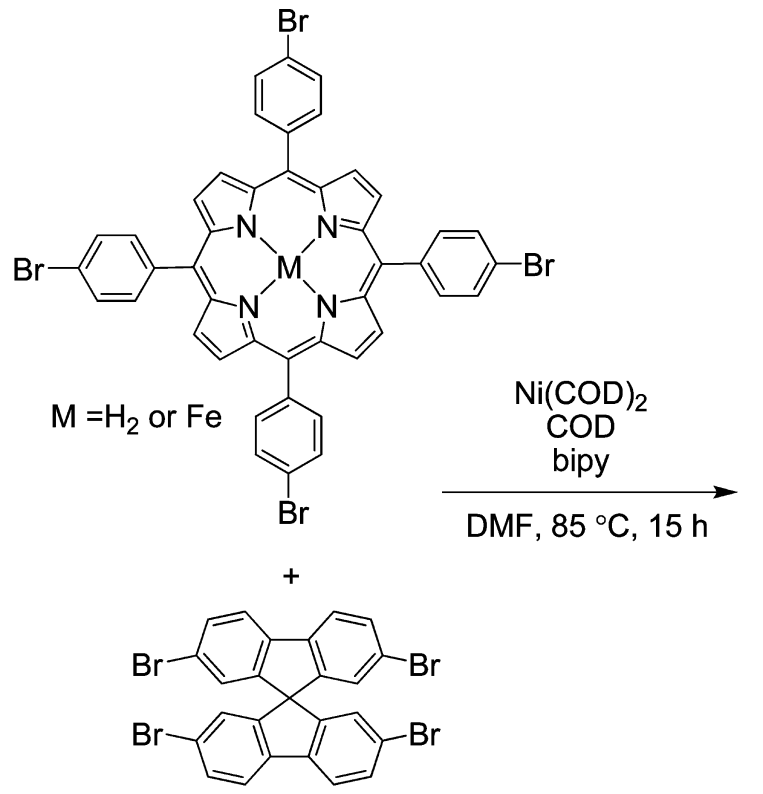

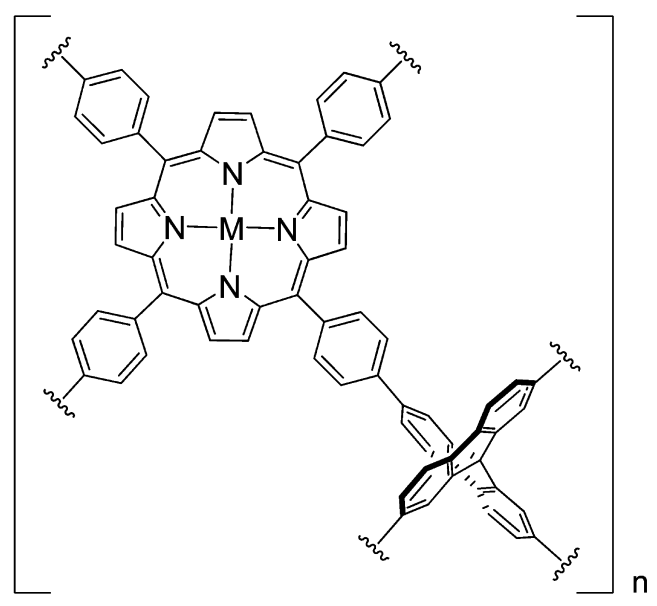

$\mathrm{HCl}, 85^{\circ} \mathrm{C}$

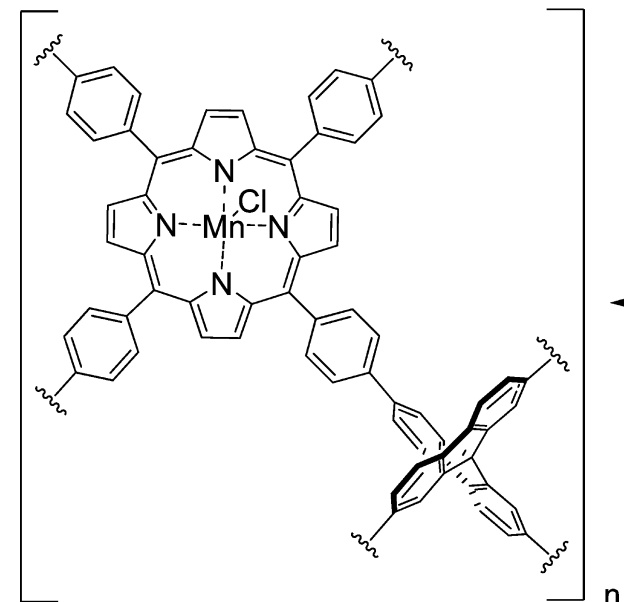

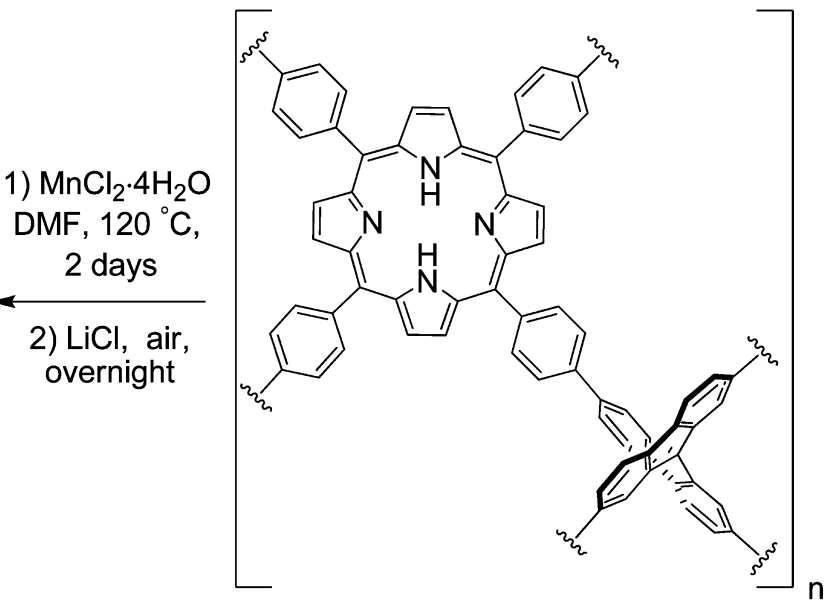

Table 1. Characterization Data for Free-Base PPOPs and Mn-PPOPs

\begin{tabular}{|c|c|c|c|c|}
\hline entries & PPOPs & $\begin{array}{l}\text { surface area } \\
\left(\mathrm{m}^{2} / \mathrm{g}\right)\end{array}$ & $\begin{array}{l}\text { total pore volume } \\
\left(\mathrm{cm}^{3} / \mathrm{g}\right)\end{array}$ & $\begin{array}{l}\text { metal loading } \\
\text { (wt \%) }\end{array}$ \\
\hline 1 & ${ }^{\mathrm{fb}} \mathrm{AFe} 1$ & 760 & 0.35 & $<0.1$ \\
\hline 2 & ${ }^{\mathrm{fb}} \mathrm{A}_{2} \mathrm{Fe} 1$ & 690 & 0.26 & 0.16 \\
\hline 3 & ${ }^{\mathrm{fb}} \mathrm{A}_{3} \mathrm{Fe} 1$ & 1130 & 0.46 & 0.14 \\
\hline 4 & ${ }^{\mathrm{fb}} \mathrm{AFe} 2$ & 620 & 0.23 & 0.37 \\
\hline 5 & ${ }^{\mathrm{fb}} \mathrm{A}_{2} \mathrm{Fe} 2$ & 1120 & 0.57 & $<0.1^{a}$ \\
\hline 6 & ${ }^{\mathrm{fb}} \mathrm{A}_{3} \mathrm{Fe} 2$ & 1390 & 0.64 & $<0.1$ \\
\hline 7 & ${ }^{\mathrm{fb}} \mathrm{A}_{2} 2$ & 1880 & 0.94 & $0.35^{b}$ \\
\hline 8 & $\mathrm{Mn}-{ }^{\mathrm{fb}} \mathrm{A}_{2} \mathrm{Fe} 2$ & 850 & 0.36 & 4.0 \\
\hline 9 & $\mathrm{Mn}-{ }^{\mathrm{fb}} \mathrm{A}_{2} 2$ & 1600 & 0.79 & 2.7 \\
\hline
\end{tabular}

${ }^{a}$ As synthesized without further demetalation. ${ }^{b} \mathrm{Ni}$ content.

expoxidation of DVB to DVBDO, with $>50 \%$ yield based on DVB (Scheme 3; Figure 5 and Figure S74 in the SI). Only a trace $(10 \mathrm{~mol} \%)$ of the incomplete oxidation product divinylbenzene monoxide (DVBMO) was found, and no epoxide ring-opening product was observed (Figure 5). A moderate amount $(\sim 24 \mathrm{~mol} \%)$ of overoxidation product (benzyladehyde derivative) exists at the end of the reaction, which may arise from the oxidative cleavage of the phenylacetylaldehyde derivative (Scheme 4$).^{48-50}$

The advantages of the PPOP environment for DVB double epoxidation clearly stand out over its homogeneous analog (TPP) $\mathrm{MnCl}$. Under the same reaction conditions (see the SI for reaction details), the homogeneous catalyst afforded a much poorer substrate conversion (Figure 6), with $\sim 30 \%$ of the alkene left in the reaction mixture after $30 \mathrm{~h}$. In addition, GC/ MS analysis shows that the major product is the partially epoxidized product DVBMO (DVBDO/DVBMO = 2:3). We attribute the higher selectivity for $\mathrm{DVBDO}$ in reactions catalyzed by $\mathrm{Mn}^{-{ }^{\mathrm{fb}}} \mathrm{A}_{2} 2$ to the high concentrations of catalyst inside its pore: after DVB entered the pore of a PPOP particle 


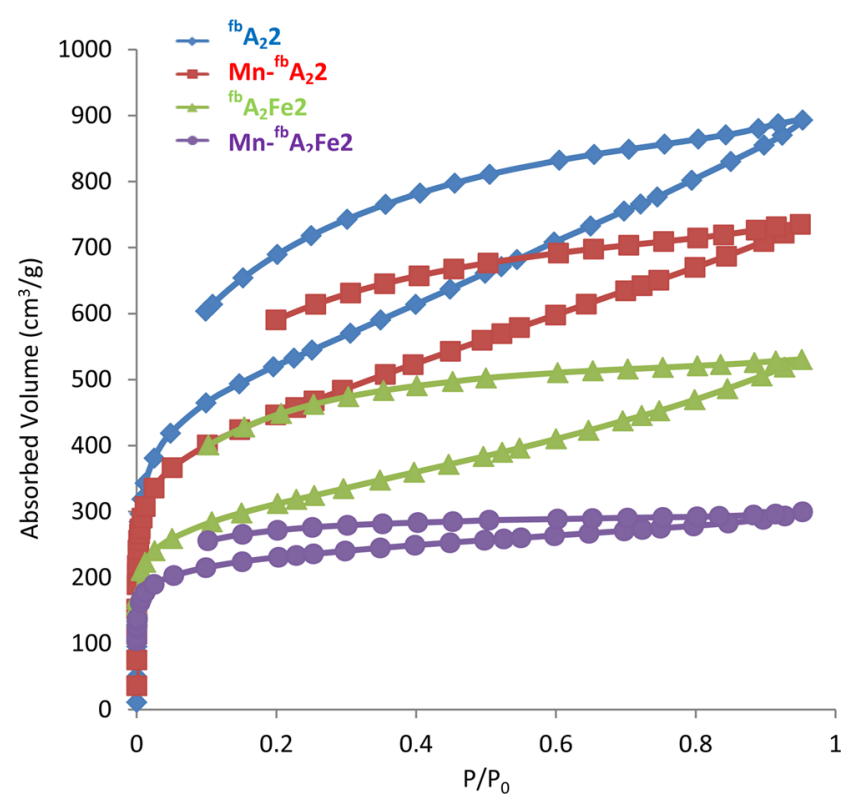

Figure 2. Stacked $\mathrm{N}_{2}$ isotherm data for ${ }^{\mathrm{fb}} \mathbf{A}_{2} \mathbf{2}$ (blue), $\mathbf{M n}-{ }^{\mathrm{fb}} \mathbf{A}_{2} \mathbf{2}$ (red), ${ }^{\mathrm{fb}} \mathrm{A}_{2} \mathrm{Fe} 2$ (green), and $\mathrm{Mn}^{-{ }^{\mathrm{fb}}} \mathrm{A}_{2} \mathrm{Fe} 2$ (purple).

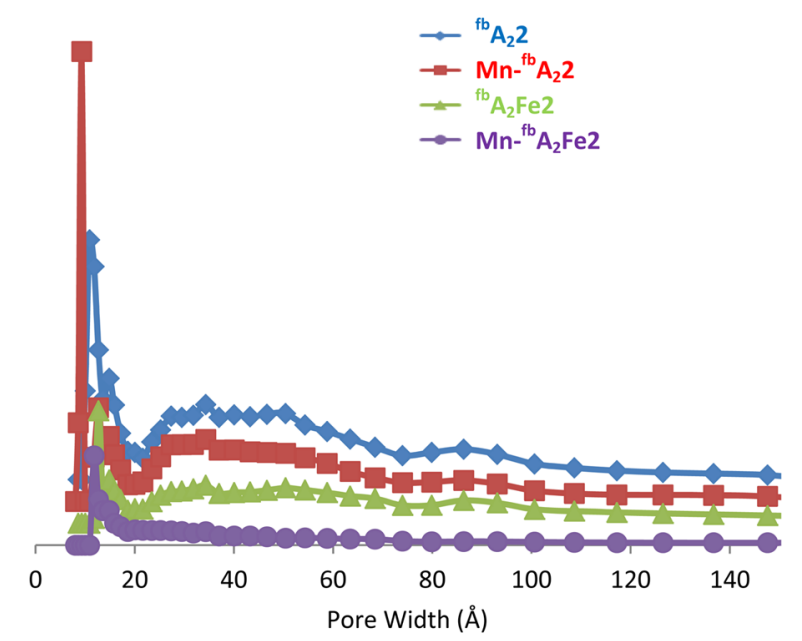

Figure 3. Stacked NLDFT (nonlocal density functional theory) pore size distribtions for ${ }^{\mathrm{fb}} \mathbf{A}_{2} \mathbf{2}$ (blue), $\mathbf{M n}^{\mathrm{fb}} \mathrm{A}_{2} \mathbf{2}$ (red), ${ }^{\mathrm{fb}} \mathbf{A}_{2} \mathrm{Fe} 2$ (green), and $\mathbf{M n}-{ }^{\mathrm{fb}} \mathbf{A}_{2} \mathbf{F e} 2$ (purple). These pore size distributions are stacked by moving $\sim 0.005 \mathrm{~cm}^{3}$ up and down for clarity. These single data can be seen in the SI with the unit on the $y$ axis as incremental pore volume.

and became oxidized, the DVBMO product was still encapsulated inside the particle and had a good chance to encounter a second metal oxo moiety prior to exiting the POP particle. Such a multicatalyst environment obviously does not exist in a reaction catalyzed by the homogeneous (TPP) $\mathrm{MnCl}$ catalyst where DVBMO is the major product.

When DVBMO is used as the substrate (Scheme 5), its epoxidation by $\mathbf{M n}-{ }^{\mathrm{fb}} \mathbf{A}_{\mathbf{2}} \mathbf{2}$ proceeds at a rate and conversion similar to that of the styrene epoxidation, indicating that the presence of the para-epoxy functional group does not significantly affect the epoxidation of the remaining styrenic $\mathrm{C}=\mathrm{C}$ bond. However, there were almost no unidentified products: DVBDO was formed in $76 \%$ yield, benzaldehyde derivatives were formed in $18 \%$ yield, and the phenylacetaldehyde products constituted the remainder of the mass balance (Figure 7). As in the case for DVB oxidation, the
Scheme 2. Epoxidation of Styrene by $M n^{-f b} \mathrm{~A}_{2} 2$ (top) and (TPP) $\mathrm{MnCl}$ (bottom)
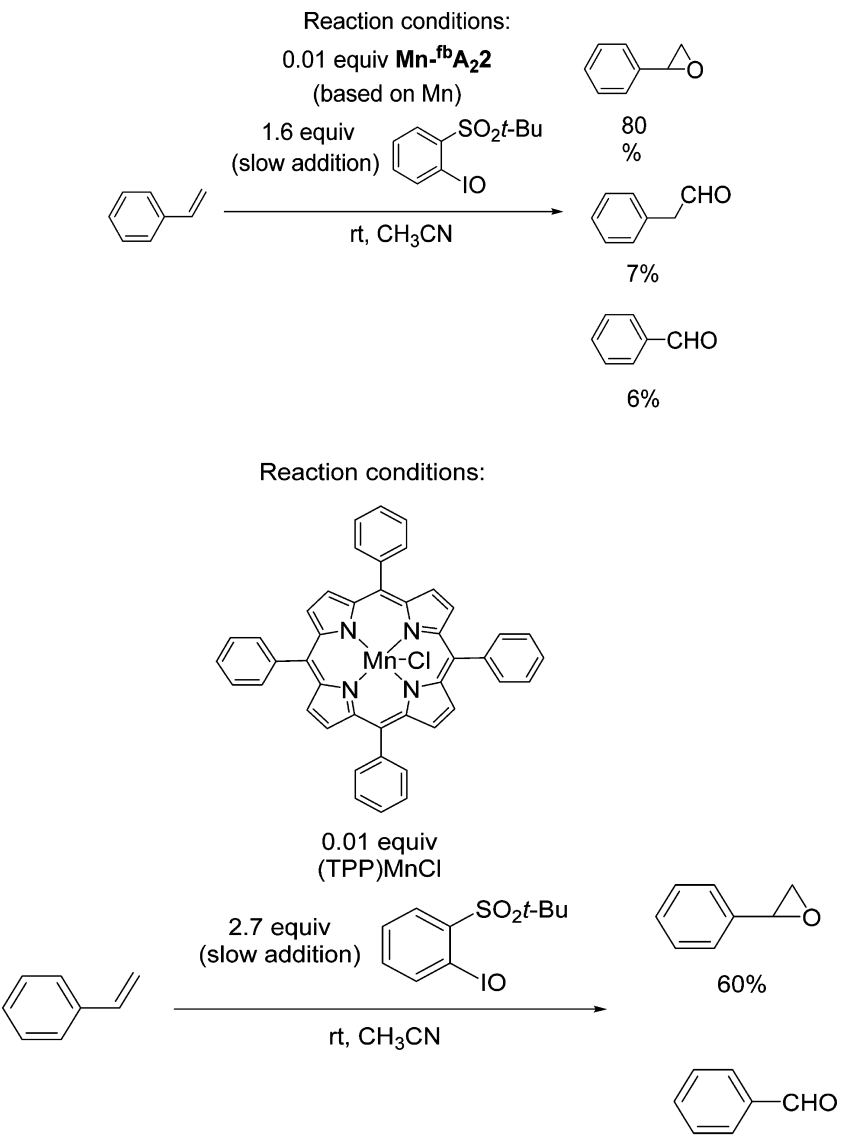

$5 \%$

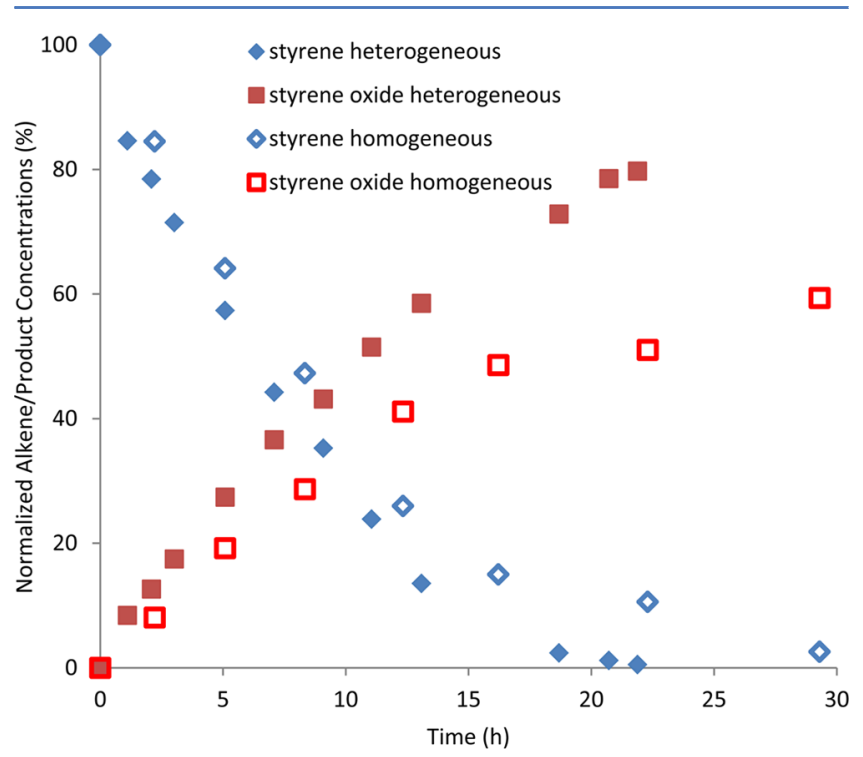

Figure 4. Comparison of styrene epoxidation using $\mathrm{Mn}^{\mathrm{fb}} \mathbf{A}_{2}$ 2, and (TPP) $\mathrm{MnCl}$.

isomerized phenylacetaldehyde products formed rather quickly, maximized at $\sim 8 \mathrm{~h}$, and then decreased. The benzaldehyde product does not form until after phenylacetaldehyde has built up, suggesting that most of the overoxidation comes from isomerization. Together with the data shown in Figure 5, these results indicate that the $20 \%$ of unidentified mass in the 
Scheme 3. Epoxidation of DVB by $\mathrm{Mn}^{\mathrm{fb}} \mathrm{A}_{2} 2$

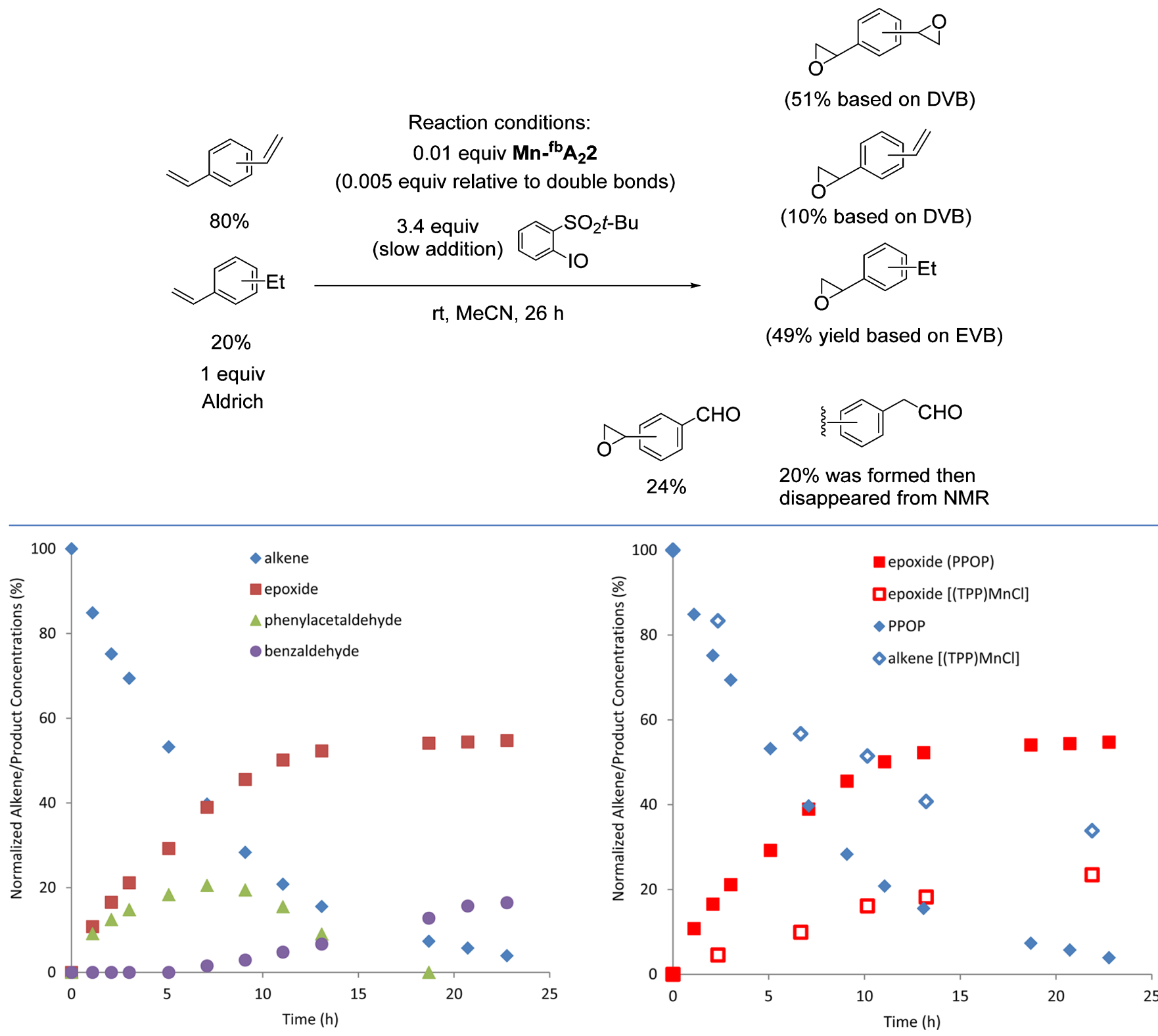

Figure 5. Plots of normalized concentrations of alkene, epoxide, phenyl acetaldehydes, and benzaldehydes as functions of time in the epoxidation DVB by $\mathbf{M n}^{\mathrm{fb}} \mathbf{A}_{2} 2$. At the end of the reaction, $\sim 20 \%$ of the reaction mass was compounds that could not be identified and thus was not accounted for in these plots. These compounds are attributed to potential side reactions of DVB (see further discussion below). The corresponding plots for $\mathbf{M n}^{\mathrm{fb}} \mathbf{A}_{2} \mathbf{F e} 2$ can be found in Figure S74 in the SI.

Scheme 4. Proposed Overoxidation Pathway oxidative cleavege

$\stackrel{[\mathrm{O}]}{\longrightarrow} \mathrm{s}$

epoxidation of DVB can be attributed to its higher susceptibility to other side reactions such as alkene polymerization in the presence of $\mathrm{Mn}$ centers with unpaired electrons. ${ }^{51-54}$

The conversion and selectivity of metalloporphyrin-catalyzed epoxidation reaction can be enhanced by the addition of

Figure 6. Plots of normalized concentrations of alkene and epoxide in the epoxidation of DVB by $\mathbf{M n}-{ }^{\mathrm{fb}} \mathbf{A}_{\mathbf{2}} \mathbf{2}$ and (TPP) $\mathrm{MnCl}$.

Scheme 5. Epoxidation of DVBMO by $\mathrm{Mn}^{-{ }^{\mathrm{fb}}} \mathrm{A}_{2} 2$

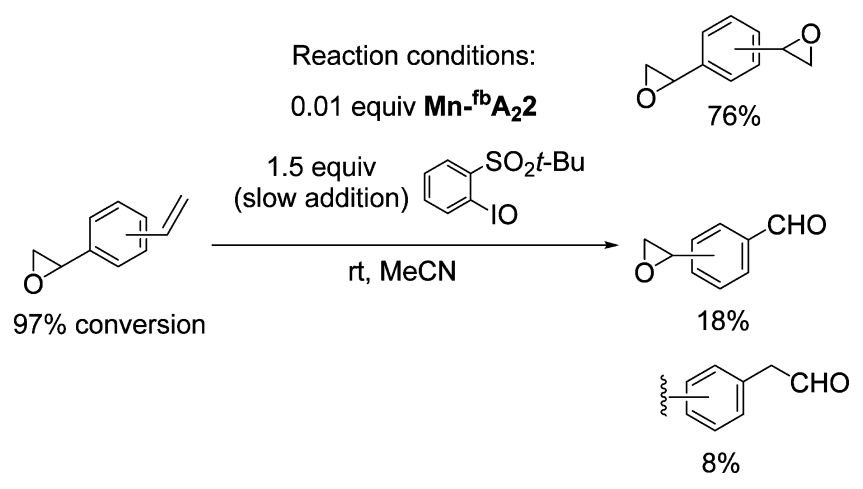

additives such as imidazole or pyridine that can coordinate to the $\mathbf{M n}$ center. ${ }^{41,42,54,55}$ This is also the case for $\mathbf{M n}^{-{ }^{\mathrm{fb}}} \mathbf{A}_{\mathbf{2}} \mathbf{2}$ : in 


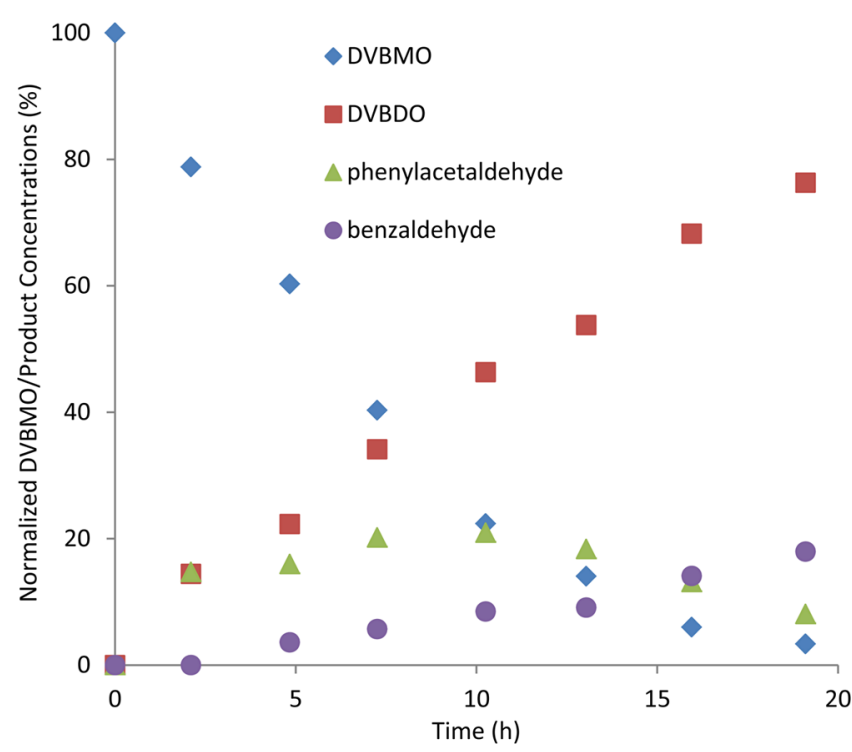

Figure 7. Plots of normalized concentrations of alkene, epoxide, phenylacetaldehyde, and benzaldehyde derivatives as functions of time in the epoxidation of DVBMO by $\mathbf{M n}-{ }^{\mathrm{fb}} \mathbf{A}_{\mathbf{2}} \mathbf{2}$.

the presence of imidazole, the overall epoxide yield is increased by an additional 19\% (20\% increase for overall DVBDO yield; see Scheme 6). This increase in yield can be attributed to the ability of imidazole to significantly inhibit the formation of isomerized and overoxidized byproducts (from 24\% to $15 \%$ for benzaldehyde) (see Figure S69 in the SI); the maximum phenylacetaldehyde yield during the reaction is down from $20 \%$ to $6 \%$ at around $7 \mathrm{~h}$ (see Figure S69 in the SI). Presumably, the coordination of imidazole to the $\mathrm{Mn}$ (porphyrin) significantly reduces its Lewis acidity and, thus, isomerization and overoxidation (Figure 8). ${ }^{56,57}$

The time-dependent selectivity profile for the epoxidation of DVB catalyzed by $\left[\mathbf{M n}-{ }^{\mathrm{fb}} \mathbf{A}_{\mathbf{2}} \mathbf{2}+\right.$ imidazole] (Figure 9) shows an early formation of DVBMO that begins to decrease after $\sim 9 \mathrm{~h}$ as DVBDO becomes dominant; however, the combined amounts of DVBMO and DVDBO up to this point are much

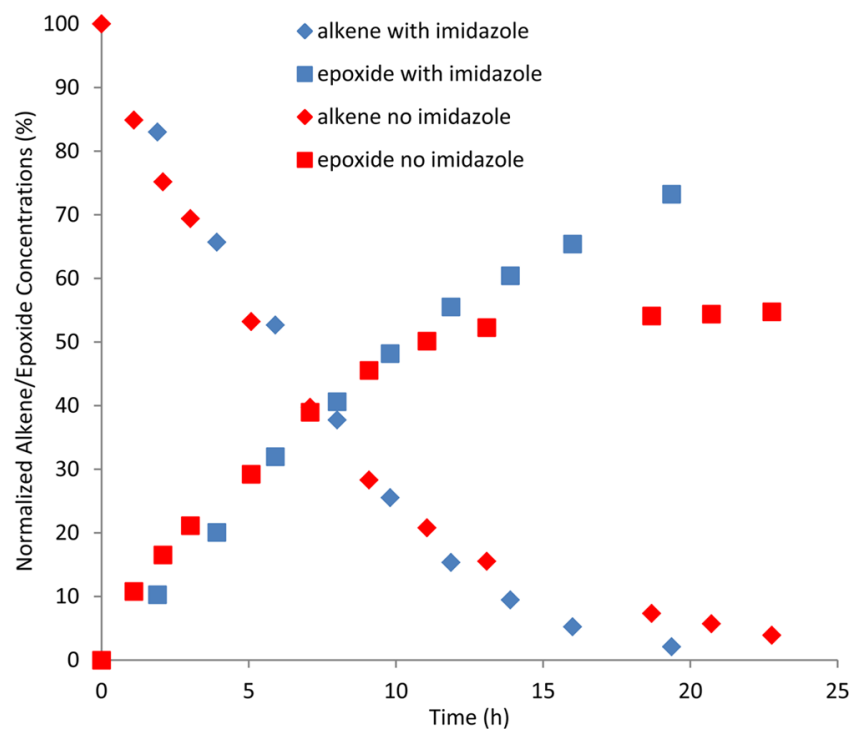

Figure 8. Normalized alkene concentration and epoxide yield for comparison of DVB epoxidation with and without imidazole.

less than the amount of converted DVB, suggesting that both DVB and the initially epoxidized DVBMO are preferentially trapped inside the pores. In this manner, there is a good chance for DVB to encounter more than one catalytic site before being released into the solution and being detected as either DVBMO or DVBDO. Indeed, DVBDO was not observed until $4 \mathrm{~h}$ into the reaction. Together, these data further support our aforementioned hypothesis that the multicatalyst porous environment is quite crucial for the selective double epoxidation of DVB. Interestingly, the effect of imidazole in the presence of $\mathbf{M n}-{ }^{\mathrm{fb}} \mathbf{A}_{2} \mathbf{F e} 2$ is much less than that for $\mathbf{M n}^{\mathrm{fb}} \mathbf{A}_{\mathbf{2}} \mathbf{2}$ (see Figure S75 in the SI). We attributed this to the lesser likelihood of the smaller pores in the latter materials to accommodate the additional imidazole ligands; that is, the smaller pores may destabilize the imidazole complex more.

It is important to note that recycling catalytic experiments are informative; however, we were unable to recycle this

Scheme 6. Epoxidation of DVB by $\mathrm{Mn}-{ }^{\mathrm{fb}} \mathrm{A}_{2} 2$ with Imidazole

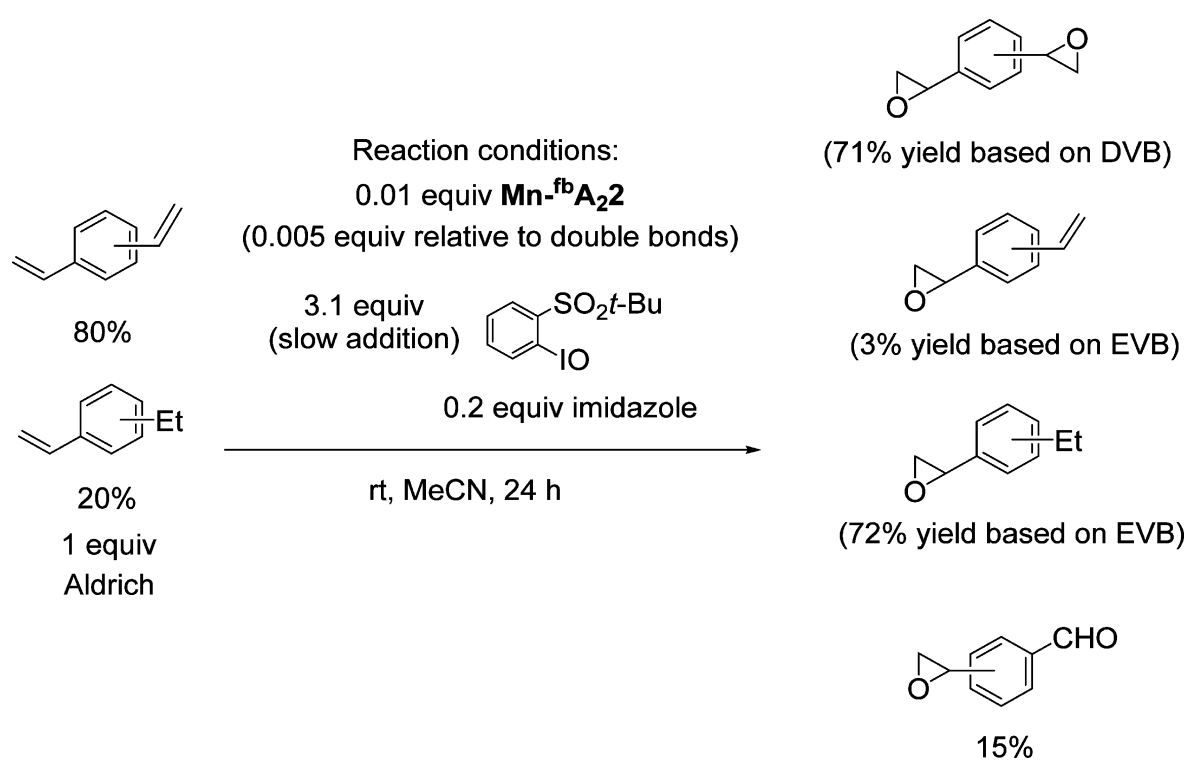




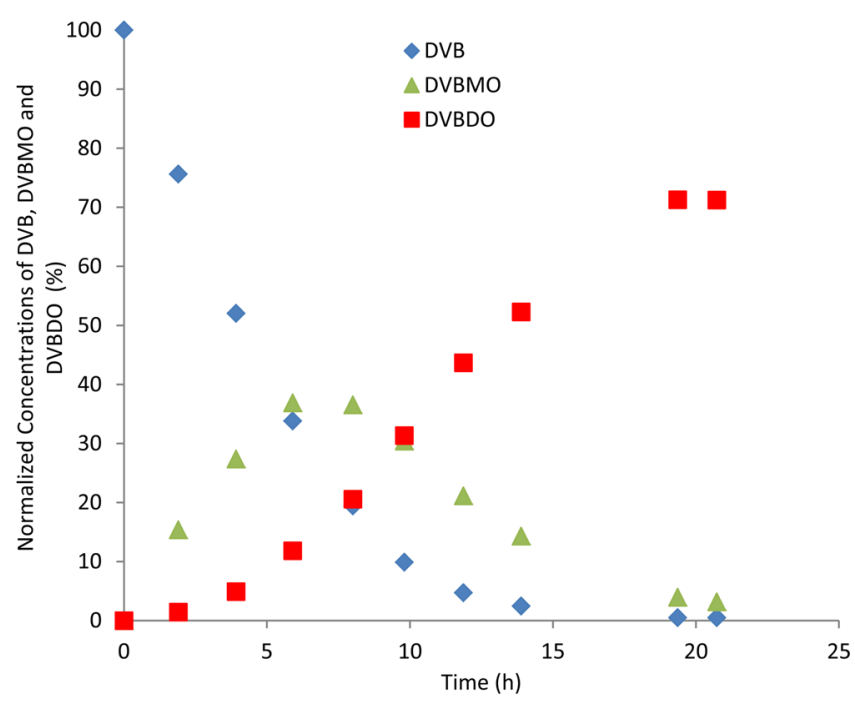

Figure 9. Plots of normalized DVB concentration, DVBDO yield (based on DVB), and DVBMO yield (based on DVB) as a function of time for the reaction in Scheme 6.

catalyst because the oxidant byproduct tert-butylsulfonyliodobenzene in the reaction was well mixed with the catalyst; the latter is actually the major part. Even after washing, we could not get clean catalysts, and we lost most of it during the washing process due to its fine powder form.

In summary, we have demonstrated the synthesis of a highly robust porphyrin-based POP material with good surface areas that can be readily metalated with $\mathrm{Mn}^{\mathrm{III}}$ and then used for the selective double epoxidation of DVB to DVBDO in the presence of 2-(tert-butylsulfonyl)iodosylbenzene. Together with reaction profiling, comparative studies against the analogous homogeneous catalyst (TPP) $\mathrm{MnCl}$ suggest that the multicatalyst porous nature of the $\mathbf{M n}^{\mathrm{fb}} \mathbf{A}_{2} \mathbf{2}$ material is the primary factor responsible for this successful double epoxidation. Such observations clearly set porous catalyst materials apart from other catalysts in which the high concentration of catalyst inside the pore plays a significant role in reaction outcome and selectivity.

\section{ASSOCIATED CONTENT}

\section{S Supporting Information}

The Supporting Information is available free of charge on the ACS Publications website at DOI: 10.1021/acscatal.5b01388.

Procedure for synthesis of PPOPs, the material characterizations, and procedures for conducting catalytic experiments (PDF)

\section{AUTHOR INFORMATION}

\section{Corresponding Authors}

*E-mail: o-farha@northwestern.edu.

*E-mail: j-hupp@northwestern.edu.

*E-mail: stn@northwestern.edu.

\section{Notes}

The authors declare no competing financial interest.

\section{ACKNOWLEDGMENTS}

This work was supported by the Dow Chemical Company. NMR measurement is supported by the National Science Foundation under CHE-1048773. We thank Dr. Patricia
Ignacio de Leon.and Prof. Justin Notestein for helpful discussions.

\section{REFERENCES}

(1) Clayton, A. M. Epoxy Resins: Chemistry and Technology, 2nd ed.; CRC Press: New York, 1988.

(2) Gulyas, G.; Bharadwaj, A. R.; Wright, R. J.; Null, M. J.; Ripplinger,

E. B. Patent WO 2011056381, May 12, 2012.

(3) Inoue, M.; Nakayama, E.; Nakamura, Y.; Rengakuji, S.; Nishibe, K. Bull. Chem. Soc. Jpn. 1991, 64, 3442-3444.

(4) Worzakowska, M. J. Appl. Polym. Sci. 2007, 103, 462-469.

(5) Marks, M. J.; Gulyas, G.; Frazier, K. A. Patent WO 2010077483, July $8,2010$.

(6) Liao, Z. K.; Boriack, C. J. U.S. Patent US6087513, July 11, 2000.

(7) Che, C. M.; Huang, J. S. Chem. Commun. 2009, 3996-4015.

(8) Dolphin, D.; Traylor, T. G.; Xie, L. Y. Acc. Chem. Res. 1997, 30, 251-259.

(9) Groves, J. T.; Haushalter, R. C.; Nakamura, M.; Nemo, T. E.; Evans, B. J. J. Am. Chem. Soc. 1981, 103, 2884-2886.

(10) Groves, J. T.; Nemo, T. E.; Myers, R. S. J. Am. Chem. Soc. 1979, $101,1032-1033$

(11) Gunter, M. J.; Turner, P. Coord. Chem. Rev. 1991, 108, 115161.

(12) Katsuki, T. Coord. Chem. Rev. 1995, 140, 189-214.

(13) Meunier, B. Chem. Rev. 1992, 92, 1411-1456.

(14) Chang, C. K.; Kuo, M. S. J. Am. Chem. Soc. 1979, 101, 34133415.

(15) Bedioui, F. Coord. Chem. Rev. 1995, 144, 39-68.

(16) Zou, C.; Zhang, T. F.; Xie, M. H.; Yan, L. J.; Kong, G. Q.; Yang, X. L.; Ma, A.; Wu, C. Inorg. Chem. 2013, 52, 3620-3626.

(17) Feng, D. W.; Gu, Z. Y.; Li, J. R.; Jiang, H. L.; Wei, Z. W.; Zhou, H. C. Angew. Chem., Int. Ed. 2012, 51, 10307-10310.

(18) Corma, A.; Garcia, H.; Llabrés i Xamena, F. X. Chem. Rev. 2010, $110,4606-4655$.

(19) Lee, J.; Farha, O. K.; Roberts, J.; Scheidt, K. A.; Nguyen, S. T.; Hupp, J. T. Chem. Soc. Rev. 2009, 38, 1450-1459.

(20) Yoon, M.; Srirambalaji, R.; Kim, K. Chem. Rev. 2012, 112, $1196-1231$.

(21) Zhang, Y.; Ying, J. ACS Catal. 2015, 5, 2681-2691.

(22) Kaur, P.; Hupp, J. T.; Nguyen, S. T. ACS Catal. 2011, 1, 819835.

(23) Costa, A. A.; Ghesti, G. F.; de Macedo, J. L.; Braga, V. S.; Santos, M. M.; Dias, J. A.; Dias, S. C. L. J. Mol. Catal. A: Chem. 2008, 282, $149-157$.

(24) Poltowicz, J.; Haber, J. J. Mol. Catal. A: Chem. 2004, 220, 4351.

(25) Chen, L.; Yang, Y.; Jiang, D. L. J. Am. Chem. Soc. 2010, 132, 9138-9143.

(26) Farha, O. K.; Shultz, A. M.; Sarjeant, A. A.; Nguyen, S. T.; Hupp, J. T. J. Am. Chem. Soc. 2011, 133, 5652-5655.

(27) Hitomi, Y.; Mukai, H.; Ohyama, J.; Shinagawa, M.; Shishido, T.; Tanaka, T. Chem. Lett. 2007, 36, 660-661.

(28) Jeong, E. Y.; Ansari, M. B.; Park, S. E. ACS Catal. 2011, 1, 855863.

(29) Shultz, A. M.; Farha, O. K.; Hupp, J. T.; Nguyen, S. T. J. Am. Chem. Soc. 2009, 131, 4204-4205.

(30) Zhang, Z. J.; Zhang, L. P.; Wojtas, L.; Eddaoudi, M.; Zaworotko, M. J. J. Am. Chem. Soc. 2012, 134, 928-933.

(31) Shultz, A. M.; Farha, O. K.; Hupp, J. T.; Nguyen, S. T. Chem. Sci. 2011, 2, 686-689.

(32) Yang, X. L.; Xie, M. H.; Zou, C.; He, Y. B.; Chen, B. L.; O'Keeffe, M.; Wu, C. D. J. Am. Chem. Soc. 2012, 134, 10638-10645.

(33) Mackintosh, H. J.; Budd, P. M.; McKeown, N. B. J. Mater. Chem. 2008, 18, 573-578.

(34) Schmidt, J.; Werner, M.; Thomas, A. Macromolecules 2009, 42, $4426-4429$

(35) Yuan, D. Q.; Lu, W. G.; Zhao, D.; Zhou, H. C. Adv. Mater. 2011, $23,3723-3725$. 
(36) Konstas, K.; Taylor, J. W.; Thornton, A. W.; Doherty, C. M.; Lim, W. X.; Bastow, T. J.; Kennedy, D. F.; Wood, C. D.; Cox, B. J.; Hill, J. M.; Hill, A. J.; Hill, M. R. Angew. Chem., Int. Ed. 2012, 51, 6639-6642.

(37) Hauser, B. G.; Farha, O. K.; Exley, J.; Hupp, J. T. Chem. Mater. 2013, 25, 12-16.

(38) Wang, X. S.; Liu, J.; Bonefont, J. M.; Yuan, D. Q.; Thallapally, P. K.; Ma, S. Q. . Chem. Commun. 2013, 49, 1533-1535.

(39) Davoras, E. M.; Coutsolelos, A. G. J. Inorg. Biochem. 2003, 94, 161-170.

(40) Merlau, M. L.; Cho, S. H.; Sun, S. S.; Nguyen, S. T.; Hupp, J. T. Inorg. Chem. 2005, 44, 5523-5529.

(41) Monfared, H. H.; Aghapoor, V.; Ghorbanloo, M.; Mayer, P. Appl. Catal., A 2010, 372, 209-216.

(42) Nam, W.; Kim, I.; Lim, M. H.; Choi, H. J.; Lee, J. S.; Jang, H. G. Chem. - Eur. J. 2002, 8, 2067-2071.

(43) Srour, H.; Le Maux, P.; Simonneaux, G. Inorg. Chem. 2012, 51, $5850-5856$

(44) Zhou, X. T.; Ji, H. B.; Xu, H. C.; Pei, L. X.; Wang, L. F.; Yao, X. D. Tetrahedron Lett. 2007, 48, 2691-2695.

(45) The Fe-metallated PPOPs show poor reactivity toward epoxidation with 2-(tert-butylsulfonyl)iodosylbenzene, tert-butyl hydroperoxide, and hydrogen peroxide. Direct synthesis of Mn-PPOP from $\mathrm{Mn}$ (porphyrin) monomers was not successful.

(46) Song, F. J.; Wang, C.; Falkowski, J. M.; Ma, L. Q.; Lin, W. B. J. Am. Chem. Soc. 2010, 132, 15390-15398.

(47) Song, F. J.; Wang, C.; Lin, W. B. Chem. Commun. 2011, 47, $8256-8258$

(48) Havare, N.; Plattner, D. A. Org. Lett. 2012, 14, 5078-5081.

(49) Venturello, C.; Gambaro, M. J. Org. Chem. 1991, 56, 59245931.

(50) Walling, C.; Eltaliawi, G. M.; Amarnath, K. J. Am. Chem. Soc. 1984, 106, 7573-7578.

(51) Colclough, R. O.; Gee, G.; Higginson, W. C. E.; Jackson, J. B.; Litt, M. J. Polym. Sci. 1959, 34, 171-179.

(52) Koumura, K.; Satoh, K.; Kamigaito, M. Macromolecules 2008, 41, 7359-7367.

(53) Wang, J. S.; Matyjaszewski, K. J. Am. Chem. Soc. 1995, 117, $5614-5615$.

(54) Nam, W.; Lee, H. J.; Oh, S. Y.; Kim, C.; Jang, H. G. J. Inorg. Biochem. 2000, 80, 219-225.

(55) Xia, Q. H.; Ge, H. Q.; Ye, C. P.; Liu, Z. M.; Su, K. X. Chem. Rev. 2005, 105, 1603-1662.

(56) de Sousa, A. N.; de Carvalho, M. E. M. D.; Idemori, Y. M. J. Mol. Catal. A: Chem. 2001, 169, 1-10.

(57) Elemans, J. A. A. W.; Bijsterveld, E. J. A.; Rowan, A. E.; Nolte, R. J. M. Eur. J. Org. Chem. 2007, 2007, 751-757. 